DOI: 10.20472/IAC.2017.032.022

WOO JE KIM

Seoul National University of Science and Technology, Korea, Republic of

JUNG KYUN KIM

Seoul National University of Science and Technology, Korea, Republic of

HYO JOO SHIN

Seoul National University of Science and Technology, Korea, Republic of

MI SUN PARK

Seoul National University of Science and Technology, Korea, Republic of

\title{
A MODEL FOR EFFICIENCY ANALYSIS OF IT MAINTENANCE SERVICES IN A COMPANY.
}

\begin{abstract}
:
IT maintenance services have an important role to operate business processes in a company. There are normally a lot of IT systems in a company and they are maintained with IT maintenance services. So, it is meaningful analysis to compare efficiency of IT maintenance services by IT system in a company.

In this paper, a model for efficiency analysis of IT maintenance services using DEA/AHP(data envelop analysis/analytic hierarchy process) is developed in a company. In this paper, the efficiency of IT maintenance services is evaluated with a DEA model which has maintenance cost and complexity of maintenance service as input factors and degree of satisfaction for maintenance service as an output factor. The complexity of maintenance service and the degree of satisfaction for maintenance service are evaluated with AHP models, respectively.

We applied this model to evaluate efficiency of IT maintenance services in an insurance company. As a result, we could suggest the best practices among the IT maintenance services and the improving directions for the inefficient IT services in the company.
\end{abstract}

\section{Keywords:}

efficiency analysis, IT maintenance service, data envelop analysis, analytic hierarchy process

JEL Classification: C61 